\title{
Formation of energy efficient start-brake modes of the frequency-controlled electric drive in production mechanism
}

\author{
Maxim Filimonov ${ }^{1, *}$, Nicolay Karnaukhov ${ }^{1}$, Eugeny Lukyanov $^{1}$, Dmitry Smyatsky ${ }^{1}$, and \\ Roman Mironenko ${ }^{1}$ \\ ${ }^{1}$ Don State Technical University, Department of Robotic and mechatronic, 344000 Rostov-on-Don, \\ Russian Federation
}

\begin{abstract}
In this article the energy efficient frequency way of starting of production mechanisms electrical drive with low power asynchronous motors (from $90 \mathrm{Wt}$ to $5 \mathrm{kWt}$ ) is proposed. To provide this With the goal of electrical losses decreasing during asynchronous motor starting the Pontryagin Maximum Principle have been applied by the authors when analysing of two-mass model of production mechanism frequency controlled electrical drive. In result of calculations for frequency controlled electrical drive of production mechanism with $90 \mathrm{Wt}$ power asynchronous motor of the model 4AA50A2 Dependencies of amplitude and frequency of supply voltage by the time are obtained. These dependencies confirm possibility of decreasing the electrical power losses with different values of motor shaft load torques. In compare with the other ways of asynchronous motor starting (for example $\mathrm{U} / \mathrm{f}=$ const) they allow to decrease the electrical losses more then two times in nominal mode.
\end{abstract}

\section{Introduction}

At the present time, in the design of production mechanisms (PM) special attention is paid to the choice of electric drive (ED), which provides energy-saving modes when performing technological processes. One of the most important energy indicators of a frequencycontrolled electric drive (FCED) based on a three-phase short-circuited asynchronous motor (AM) is the total losses in the autonomous voltage inverter (AVI) -AM system, determined by dynamic modes: starting and braking, reversing of the PM motion. Energy losses in such modes can be represented by the instantaneous power of total losses [1] in the elements of the energy channel in the form of an integral characteristic.

$$
W_{E}=\int_{0}^{t_{S}} P_{E} d t=\int_{0}^{t_{S}}\left(P_{C}+P_{M}\right) d t
$$

\footnotetext{
* Corresponding author: maxfil2006@yandex.ru
} 
where $P_{C}$ - losses in the converter, supply and discharge circuits; $P_{M}$ - total electrical losses in $\mathrm{AM} ; t_{S}$ - start time.

The total energy losses $W_{E}$ consist of the instantaneous components of the losses: electrical, magnetic, mechanical, and additional with different control laws of the AM FCED. The need to develop such control laws is due to the peculiarities of the formation asynchronous motor (AM) mechanical characteristics in the zone of "low and creeping" [2, 3] speeds, with the difference in the duration of activation (DA) from $25 \%$ or more [4].

\section{Problem statement}

When implementing such modes, particular importance is the method of how the autonomous inverter is forming voltage (AVI) for supply AM with minimal harmonic components and the choice of an expedient scalar control law [2, 5-7]. To find a solution to the problem, the authors considered a calculation model of the mechanical part of PM with AM (Figure 1) in the form of a two-mass chain system [8].

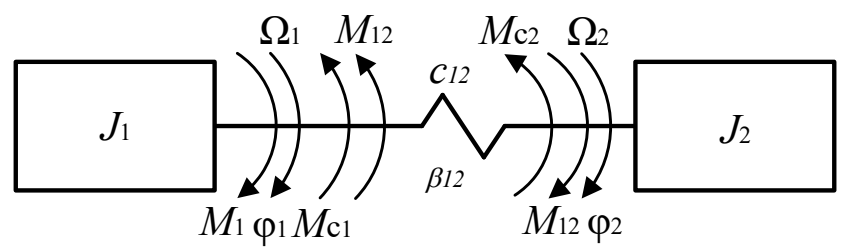

Fig. 1. The calculation model of the mechanical system of the electric drive PM.

Taking into account the accepted assumptions [2,9] and the calculation model, you can create a mathematical model of FCED using the equations of AM (in a rotating coordinate system) for the PM link in the form [2, 9]:

$$
\begin{aligned}
& {\left[\begin{array}{l}
i_{1 \alpha}^{\prime} \\
i_{2 \alpha}^{\prime} \\
i_{1 \beta}^{\prime} \\
i_{2 \beta}^{\prime}
\end{array}\right]=\left[\begin{array}{cccc}
-c r_{1} & d r_{2}^{\prime} & \Omega_{1} d L_{12} & \Omega_{1} d L_{2} \\
d r_{1} & -b r_{2}^{\prime} & -\Omega_{1} b L_{12} & -\Omega_{1} b L_{2} \\
-\Omega_{1} d L_{12} & -\Omega_{1} d L_{2} & -c r_{1} & d r_{2}^{\prime} \\
\Omega_{1} b L_{12} & \Omega_{1} b L_{2} & d r_{1} & -b r_{2}^{\prime}
\end{array}\right] \times\left[\begin{array}{c}
i_{1 \alpha} \\
i_{2 \alpha} \\
i_{1 \beta} \\
i_{2 \beta}
\end{array}\right]+\left[\begin{array}{cc}
c & 0 \\
-d & 0 \\
0 & c \\
0 & -d
\end{array}\right] \times\left[\begin{array}{l}
u_{1 \alpha} \\
u_{1 \beta}
\end{array}\right]} \\
& J_{1} \cdot \Omega_{1}^{\prime}=3 / 2 \cdot p \cdot L_{12} \cdot\left(i_{1 \beta} i_{2 \alpha}-i_{1 \alpha} i_{2 \beta}\right)-\mathrm{M}_{12}-\mathrm{M}_{C 1} ; J_{2} \cdot \Omega_{2}^{\prime}=\mathrm{M}_{12}-\mathrm{M}_{C 2} ; \\
& M_{12}=c_{12} \cdot\left(\varphi_{1}-\varphi_{2}\right)+\beta_{12} \cdot\left(\Omega_{1}-\Omega_{2}\right) ; \varphi_{1}^{\prime}=\Omega_{1} ; \varphi_{2}^{\prime}=\Omega_{2} ; \varphi_{S}^{\prime}=k_{S} \cdot \Omega_{2} ; \\
& u_{1 \alpha}=U_{R E F} \cdot \gamma \cdot \cos (v \cdot t) ; u_{1 \beta}=U_{R E F} \cdot \gamma \cdot \sin (v \cdot t) ; L_{1}=L_{12}+L_{\sigma 1} ; \\
& L_{2}=L_{12}+L_{\sigma 2} ; b=L_{1} /\left(L_{1} L_{2}-L_{12}^{2}\right) ; c=L_{2} /\left(L_{1} L_{2}-L_{12}^{2}\right) ; d=L_{12} /\left(L_{1} L_{2}-L_{12}^{2}\right) \text {, }
\end{aligned}
$$

where $i_{1 \alpha}, i_{2 \alpha}, i_{1 \beta}, i_{2 \beta}$ - currents in the stator and rotor windings along the coordinate axes $\alpha$ and $\beta ; u_{1 \alpha}, u_{1 \beta}$ - voltages on the stator windings along the $\alpha$ and $\beta$ axes; $r 1, r_{2}^{\prime}$ - stator active resistance and reduced rotor active resistance, respectively; $L_{1}, L_{2}, L_{12}$ - stator and rotor inductances and mutual inductance; $L \sigma_{1}, L \sigma_{2}$ - leakage inductances of stator and rotor windings; $p$ is the number of pole pairs of the stator AM; $U_{R E F}, \gamma, v$ - nominal and relative values, input voltage frequency; $c_{12}, \beta_{12}$ - coefficients of stiffness and viscous internal friction between the links of the driving and driven shaft; $\varphi_{S}, k_{S}$ - displacement, the conversion factor (gain) of the output link along the way; $M_{12}$ is the moment of elastic interaction; $M_{C 1}, M_{C 2}$ - the moment of resistance on the shaft AM and the static moment of the load; $J_{1}, J_{2}$ - moments of inertia of the drive and driven shafts PM; $\varphi_{1}, \varphi_{2}$ - angles of 
rotation of the driving and driven shafts, $\Omega_{1}, \Omega_{2}$ - angular velocities of the driving and driven shafts PM.

For research the model (2) in order to minimize electrical losses in FCED [8, 10] (during the start and braking of the AM), we introduce the functional $\Phi$, as an estimate of these losses by the square of the relative value of the input voltage, in the form:

$$
\text { Fun }=\int_{t_{0}}^{T} \gamma^{2} d t \rightarrow \min
$$

Applying the Pontryagin maximum principle to solve equation (3), we determine the relative frequency $v_{\min }$ and the input voltage value $\gamma_{\min }$, which delivers a minimum to the functional (3):

$$
\begin{gathered}
v_{\min }=1 / t \cdot \operatorname{arctg}\left(\left(\Psi_{3} \cdot c-\Psi_{4} \cdot d\right) /\left(\Psi_{1} \cdot c-\Psi_{2} \cdot d\right)\right) \\
\gamma_{\min }=U_{\mathrm{H}} / 2 \cdot \sqrt{\left(\Psi_{1} \cdot c-\Psi_{2} \cdot d\right)^{2}+\left(\Psi_{3} \cdot c-\Psi_{4} \cdot d\right)^{2}} .
\end{gathered}
$$

\section{Problem solution}

Calculations of modes that ensure reduction of electrical losses during the start-up of the AM, were carried out for an electric motor 4AA50A2У3 [11] $\left(P_{R E F}=90 \mathrm{~W} ; P_{S}=93.75 \mathrm{VA}\right.$; $U_{\text {PHREF }}=127 \mathrm{~V} ; f_{C}=50 \mathrm{~Hz} ; \mathrm{Rs}=37.15 \mathrm{Ohm} ; \mathrm{Ls}=0.102 \mathrm{H} ; \mathrm{Rr}=25.69 \mathrm{Ohms} ; \mathrm{Lr}=0.102$ $\mathrm{H} ; \mathrm{Lsr}=1.69 \mathrm{H} ; \mu \mathrm{r}=0.00025 ; \mathrm{Jr}=0.2454 \cdot 10-4 \mathrm{~kg} \mathrm{~m} 2 ; \mathrm{p}=1$ ) with a change in load torque from 0 to $M_{R E F}$.

Figure 2 shows the calculated dependencies (to determine the law) of changes in the relative values of the frequency $v$ (curve 1) and the input voltage $\gamma$ (curve 2) AM on time, during the start with minimum loss. The dependences show that when starting at the minimum loss, the relative frequency of the input voltage of the AM varies from $1.26 \cdot v_{R E F}$ to the nominal value $v_{R E F}=1$, and the relative voltage from $0.28 \cdot \gamma_{R E F}$ to the nominal value $\gamma_{R E F}=1$. This type of change in $v_{R E F}$ and $\gamma_{R E F}$ shows that start with minimum loss is significantly different from the frequency start, when $v$ and $\gamma$ change from 0 to the nominal value according to the law $\gamma / v=$ const, and also differs from the direct start, at $v=v_{R E F}$, and $\gamma=\gamma_{R E F}$ over the entire time interval for the start of AM. For comparison, the following modes were investigated: direct start of AM, scalar for a given control law ( $\mathrm{U} / \mathrm{f}=$ const) and with minimal losses (according to the accepted criterion). For all types of start and the case of nominal load moment, the total thermal electric losses of power $\left(P_{E}\right)$ and energy $\left(W_{E}\right)$ in AM (figure 3) are calculated by the formula:

$$
P_{E}=\left(i_{1 \alpha}^{2}+i_{1 \beta}^{2}\right) \cdot r_{1}+\left(i_{2 \alpha}^{2}+i_{2 \beta}^{2}\right) \cdot r_{2}^{\prime} ; W_{E}=\int_{t_{o}}^{T} P_{E} d t
$$

For the calculated dependencies, the following numerical designations are introduced: 1when starting with the minimum of losses, 2 - at the direct start, 3 - at the frequency start.

Analysis of the dependence of the total losses of electricity (Figure 3) shows:

- direct and scalar ( $\mathrm{U} / \mathrm{f}=\mathrm{const}$ ) starts cause almost identical electric losses in the stator and rotor windings of the AM (curves 2 and 3, respectively);

- the discrepancy between curves 2 and 3 is not more than $23 \%$ at a static load of $0.85 M_{R E F}$

Therefore, the reduction of the total electrical losses in AM (when frequency control of the AVI-AM system with minimal electrical losses) is possible with a corresponding change in the parameters $v_{R E F}$ and $\gamma_{R E F}$ from 0 to the nominal value according to the law $\gamma / v=$ const, and also differ from direct start, with $\nu=v_{R E F}$, and $\gamma=\gamma_{R E F}$ over the entire time interval for 


\section{EEESTS-2019}

the start of AM. This confirms the effectiveness of the decision taken on the implementation of repeat - short term modes of operation of FCED PM when performing the technological process.

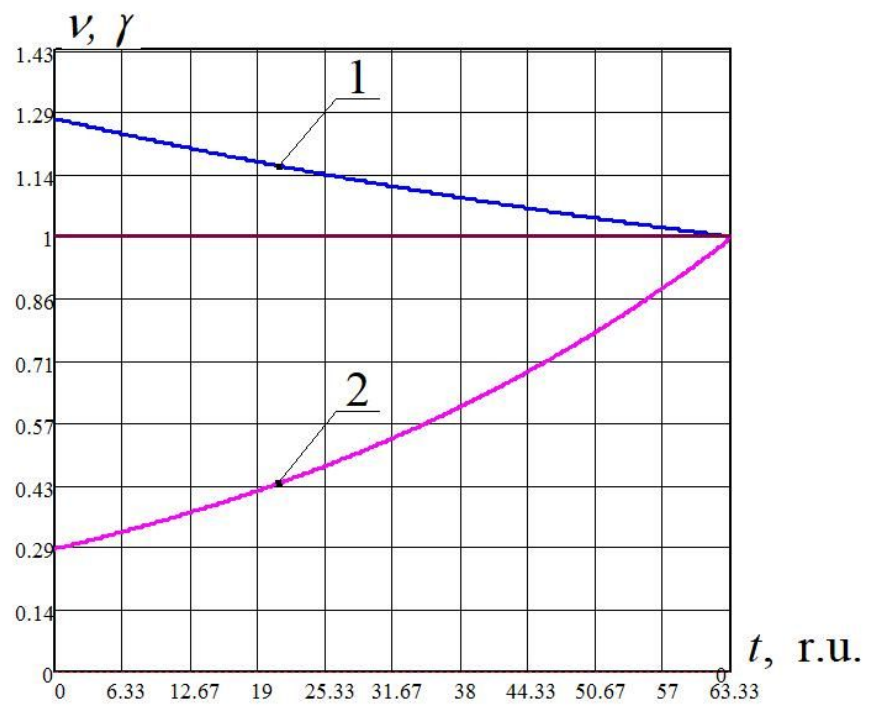

Fig. 2. The change in the relative frequency and voltage at the start of AM with minimal electrical losses.

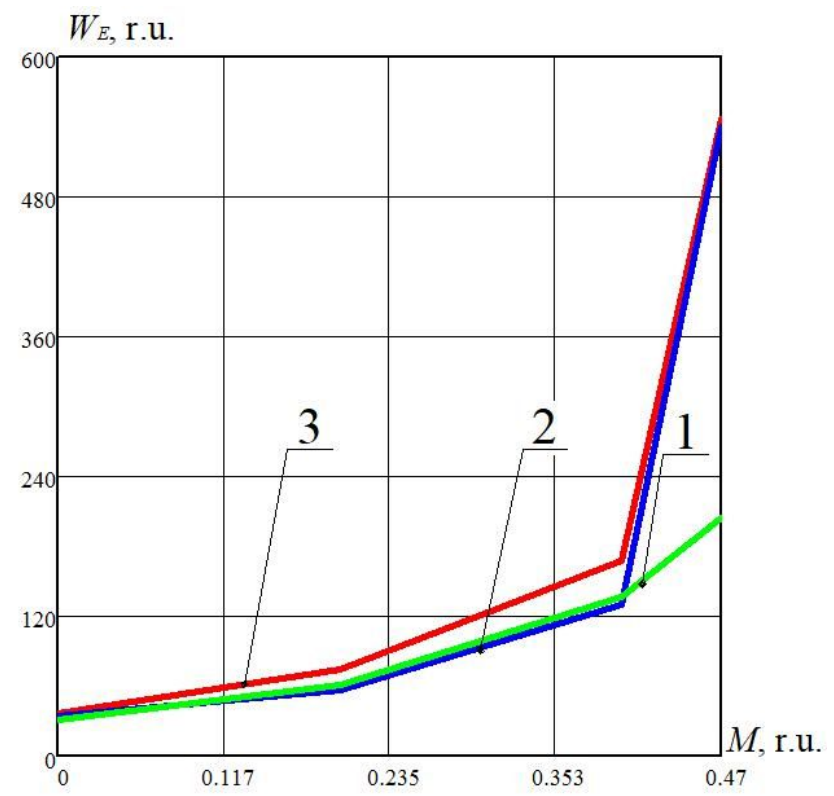

Fig. 3. Total energy loss in the function of the loading moment, during the start of AM.

\section{Conclusion}

Therefore, we can conclude that: 
- Application of the obtained dependences for the relative frequency vmin and the input voltage value $\gamma$ min during the start-up of the AM for the minimum loss of electrical energy makes it possible to effectively implement repeat - short term operation modes of FCED PM. This type of change in $v_{R E F}$ and $\gamma_{R E F}$ shows that start with minimum loss is significantly different from the frequency start, when $v$ and $\gamma$ change from 0 to the nominal value according to the law $\gamma / v=$ const, and also differs from the direct start, at $v=v_{R E F}$, and $\gamma=\gamma_{R E F}$ over the entire time interval for the start of AM.

- For the majority of PM with a nominal power AM from $P_{R E F}=90 \mathrm{~W}$ to $5 \mathrm{~kW}$ and more, it is expedient to use the scalar control law $\mathrm{U} / \mathrm{f}=$ const during start-up, which ensures minimum electrical losses in comparison with other known scalar control and direct start laws.

\section{References}

1. I.Y. Braslavsky, Z.Sh. Ishmatov, V.N. Polyakov, Energosberegayushhij asinxronnyj elektroprivod [Energy-saving asynchronous electric drive] (ACADEMA, Moscow, Publ, 2004) (in Russian).

2. Sokolovskij G.G. Elektroprivody peremennogo toka s chastotnym regulirovaniem.[AC drives with frequency regulation] (ACADEMA, Moscow, 2006) (in Russian).

3. N.F. Karnaukhov, M.N. Filimonov, A.I. Izyumov, Vestnik DSTU, 6 (67), 76 (2012)

4. M.N. Filimonov, N.F. Karnaukhov, D.A. Smyatsky, Izvestiya vysshikh uchebnykh zavedeniy. Elektromekhanika, 61, 2, 70 (2018) (in Russian).

5. M.S.A. Dahidah and V.G. Agelidis, IEEE Trans. on Power Electronics, 23, 4, (2008)

6. N. Van Nho \& M. J. Youn, International Conference on Power Electronics and Drives Systems, PEDS 2005, 2, 1419 (2005)

7. W. Subsingha, Energy Procedia, 89, 137 (2016)

8. N.F. Karnaukhov, M.N. Filimonov, R.S. Mironenko, Vestnik DSTU, 17, 3 (90), 78 (2017)

9. N.F. Karnauhov Chastotno-upravlyaemyj asinhronnyj elektroprivod mekhatronnyh sistem. Osnovy raschyota $i$ proektirovaniya [Frequency-controlled asynchronous electric mechatronic systems. Basics of design and calculation] (Rostov-on-Don, 2009) (in Russian).

10. N.F. Karnaukhov, V.A. Prus, M.N. Filimonov, Trudy VIII Mezhdunarodnoj nauchnotekhnicheskoj konferentsii DGTU [Proceedings of the VIII International Scientific and Technical Conference DSTU], Rostov-on-Don, III, 219 (2007) (in Russian).

11. N.F. Karnaukhov, M.N. Filimonov, Y.V. Pudova, Vestnik DSTU, 10, 4 (47), 569 (2010) 